\title{
Profil PSY-5 scales dari MMPI-2 adaptasi Indonesia pada mahasiswa Semester 1 TA 2013/2014 Fakultas Kedokteran Universitas Sam Ratulangi Manado
}

\author{
${ }^{1}$ Marsevino Raintama \\ ${ }^{2}$ Lisbeth F. J. Kandou \\ ${ }^{2}$ Barnabas H. R. Kairupan \\ ${ }^{1}$ Kandidat Skripsi Fakultas Kedokteran Universitas Sam Ratulangi Manado \\ ${ }^{2}$ Bagian Psikiatri Fakultas Kedokteran Universitas Sam Ratulangi \\ Email: marsevino_raintama@rocketmail.com
}

\begin{abstract}
A college student is constantly facing problems from internal source as well as external source that can affect both academic and non-academic field. Those problems can disturb the student's mental health. One of the methods to identify a person's mental status is a personality test. This study used Personality Psychopathology Five (PSY-5) scales from the Indonesian adaptation of MMPI-2 to obtain the mental status of college students of $1^{\text {st }}$ semester academic year of 2013/2014 Medical Faculty University of Sam Ratulangi. This was a descriptive study with a cross sectional survey. The results showed that of 101 respondents based on the socio-demographic the majority were females $(72.28 \%$ ), aged 18 years $(88.12 \%)$, originated from Sulawesi Utara $(64.36 \%)$, belonged to a tribe from out of Sulawesi $(53.47 \%)$, had a sibling $(33.67 \%)$, first child of the family $(40.59 \%)$, and parents worked at the private sector. The distribution based on the academic characteristics of the respondents showed that the majority applied with the T2 and had high prestation index varied from ordinary to high (32.68\% to 33.66\%). Based on the distribution of Psy-5 scales of 101 respondents, there were some PSY-5 sub-scales that had high values as follows: AGGR (5.94\%), PSYC (6.93\%), DISC (7.92\%), NEGE (12.87\%), and INTR (16.83\%). College students with high values of PSY-5 scales could show particular types of personality that varied in every PSY-5 sub-scales. It is suggested that students who had high scale values should be paid attention from the head of the faculty to prevent the occurence of mental disorders.
\end{abstract}

Keywords: personality test, PSY-5 scales, MMPI-2, college students

\begin{abstract}
Abstrak: Mahasiswa cenderung berhadapan dengan masalah baik yang berasal dari sumber internal maupun eksternal, yang dapat memengaruhi prestasi bidang akademis maupun nonakademis. Setiap masalah tersebut dapat menimbulkan pengaruh pada kesehatan mental mahasiswa. Salah satu cara untuk mengidentifikasi status mental seseorang ialah dengan menggunakan tes kepribadian. Penelitian ini menggunakan Personality Psychopathology Five (PSY-5) scales dari MMPI-2 adaptasi Indonesia untuk mengetahui status mental dari mahasiswa semester 1 TA 2012/2013 FK UNSRAT. Jenis penelitian ialah deskriptif dan dilakukan survei secara potong lintang. Hasil penelitian memperlihatkan 101 responden berdasarkan sosiodemografik terbanyak ialah perempuan $(72,28 \%)$, usia 18 tahun $(88,12 \%)$, asal daerah Sulawesi Utara $(64,36 \%)$, suku di luar Sulawesi $(53,47 \%)$, jumlah bersaudara 2 orang $(33,67 \%)$, anak pertama dalam keluarga $(40,59 \%)$, dan pekerjaan orang tua sebagai pekerja swasta $(43,56 \%)$. Distribusi berdasarkan karakteristik akademis didapatkan dari 101 responden terbanyak mengikuti jalur T2 dan memiliki nilai indeks prestasi SMA sedang dan baik (32,68\% dan 33,66\%). Simpulan: Pada distribusi skala Psy-5 dari 101 responden ditemukan beberapa sub skala PSY-5 yang tinggi antara lain AGGR (5,94\%), PSYC (6,93\%), DISC (7,92\%), NEGE (12,87\%), dan INTR $(16,83 \%)$. Mahasiswa dengan skala PSY-5 yang tinggi didapati beberapa jenis kepribadian khas yang berbeda-beda pada tiap sub skala PSY-5. Bagi setiap mahasiswa yang menunjukkan profil skala yang tinggi seharusnya mendapat perhatian dari pimpinan fakultas untuk mencegah tmbulnya gangguan jiwa.
\end{abstract}

Kata kunci: tes kepribadian, PSY-5 scales, MMPI-2, mahasiswa 
Seorang mahasiswa ialah salah satu contoh manusia yang cenderung sering berhadapan dengan masalah, meskipun terkadang masalah tersebut masih dapat dinilai ringan. Sumber masalah yang sering dialami oleh mahasiswa dapat dibagi menjadi dua sumber yaitu: sumber internal dan sumber eksternal. Sumber internal dapat berupa kondisi diri, kecerdasan, bakat, minat, fisik, nilai, kreativitas, pribadi, keterampilan belajar dan lain sebagainya, sedangkan sumber eksternal dapat berupa kondisi fisik dan sosioemosional di lingkungan keluarga, kampus, hubungan dengan teman/dosen/keluarga, status perguruan tinggi, dan sarana belajar. ${ }^{1}$

Menurut hasil Laporan Riset Kesehatan Dasar (RISKESDAS) Indonesia pada tahun 2007, didapatkan prevalensi gangguan mental emosional pada kelompok umur diatas 15 tahun adalah $11,6 \%$ dengan jenis kelamin terbanyak pada perempuan yaitu $14,0 \%$ dan laki-laki sebanyak $9,0 \%$ serta prevalensi pada pelajar adalah $8,0 \% .^{2}$ Mahasiswa pada semester 1 lebih dituntut untuk melakukan adaptasi pada kehidupan kampus, mencoba memperbaharui hubungan sosial dengan teman-teman baru dan menjalani kuliah dan metode pembelajaran yang cukup berbeda dari tingkat SMA sehingga seringkali menjadi stresor yang menjadi penyebab gangguan mental. Melihat kenyataan yang dipaparkan diatas maka pemeriksaan status mental pada mahasiswa penting dilakukan untuk mendeteksi dini adanya gangguan mental.

Minnesota Multiphasic Personality Inventory-2 (MMPI-2) merupakan salah satu tes kesehatan mental yang saat ini semakin sering digunakan untuk mencoba mengevaluasi kondisi kesehatan mental seseorang berupa fungsi kepribadian, keadaan emosional saat ini dan tingkat keparahan psikopatologi. ${ }^{3}$ Hathaway dan McKinly berpendapat bahwa tes kepribadian dengan menggunakan kuesioner dalam sebuah grup merupakan cara yang lebih efisien dan handal untuk mendapatkan hasil psychodiagnostic yang terpercaya. ${ }^{4}$ Keunggulan dari MMPI-2 ialah adanya Validity Scales yang dapat menilai apakah peserta tes telah menjawab pertanyaan sesuai dengan kondisi peserta serta dilengkapi dengan skala monitoring terhadap biasnya penelitian. ${ }^{5}$

Berdasarkan latar belakang penulis memandang penting adanya penelitian mengenai status mental pada mahasiswa semester 01 Tahun Akademik 2013/2014 di Fakultas Kedokteran Universitas Sam Ratulangi, Manado dengan menggunakan Minnesota Multiphasic Personality Inventory-2 (MMPI-2) untuk mengetahui profil Personality Psychopathology Five scales (PSY-5).

\section{METODE PENELITIAN}

Jenis penelitian ini ialah deskriptif dan melakukan survei secara potong lintang. Penelitian ini dilakukan dengan memberikan kuesioner kepada mahasiswa Semester 1 Tahun Akademik 2013/2014 di Fakultas Kedokteran Universitas Sam Ratulangi Manado, dan dilaksanakan dalam periode bulan November 2013-Januari 2014. Populasi ialah seluruh mahasiswa semester 1 yang berjumlah 259 orang. Kriteria inklusi ialah individu yang terdaftar sebagai mahasiswa semester 1, aktif kuliah, bersedia menjadi responden, dan berusia 18 tahun keatas sedangkan kriteria eksklusi ialah memiliki penyakit fisik yang berat dan tidak bisa hadir pada saat pengisian kuesioner. Sebanyak 145 mahasiswa yang memenuhi kriteria inklusi sedangkan yang hadir mengikuti tes MMPI-2 sebanyak 126. Hasil tes MMPI-2 yang valid sebanyak 101 orang.

Variabel penelitian yaitu Personality Psychopathology Five scales (PSY-5), sosio-demografik (jenis kelamin, umur, pekerjaan orang tua, asal daerah, jumlah saudara dan suku bangsa), profil akademik (jalur masuk universitas, indeks prestasi SMA, modul yang tidak lulus pada saat ujian tengah semester). Jenis serta cara pengambilan data yang didapatkan ialah data primer dan sekunder, melalui tahap persiapan dan pelaksanaan.

Kuesioner dibagikan kepada mahasiswa semester 1 disertai penjelasan 
mengenai tujuan dan manfaat pengumpulan data penelitian oleh ahli (dosen pembimbing). Kuesioner dibagikan kepada mahasiswa dan diberi waktu selama 90 menit untuk mengisi. Setelah semua pertanyaan telah terisi jawaban, mahasiswa diberikan waktu selama 30 menit untuk memastikan kembali semua pertanyaan telah diisi dengan benar dan tepat, kemudian kuesioner dikumpul.

Data dianalisis dengan menggunakan analisa univariat. Data Personality Psychopathology Five scales (PSY-5) MMPI-2 diserahkan pada pemeriksa untuk diinterpretasikan dan diolah dengan program khusus. Program Excel digunakan untuk data sosio-demografi dan data hasil interpretasi MMPI-2.

\section{HASIL PENELITIAN}

Penelitian dilakukan pada mahasiswa semester 1 tahun akademik 2013/2014 Fakultas Kedokteran program studi Kedokteran Umum Universitas Sam Ratulangi Manado yang masuk kriteria inklusi eksklusi yaitu berjumlah 126 orang, namun berdasarkan skala validitas dari MMPI-2 hanya 101 orang yang memiliki hasil valid dan menjadi responden hasil penelitian ini. Data PSY-5 scales yang dipaparkan ialah data dari 101 responden yang akurat dan valid berdasarkan skala validitas dan di interpretasikan dengan skor tinggi ( $\mathrm{T}$ score $>65$ ), Normal ( $\mathrm{T}$ score 4165), dan Rendah ( $\mathrm{T}$ score $\leq 40$ ). Gambar 1 menunjukkan bahwa persen-tase subyek penelitian dengan skor AGGR tinggi $5,94 \%$, normal $84,15 \%$, dan rendah $9,90 \%$.

\section{AGGR}

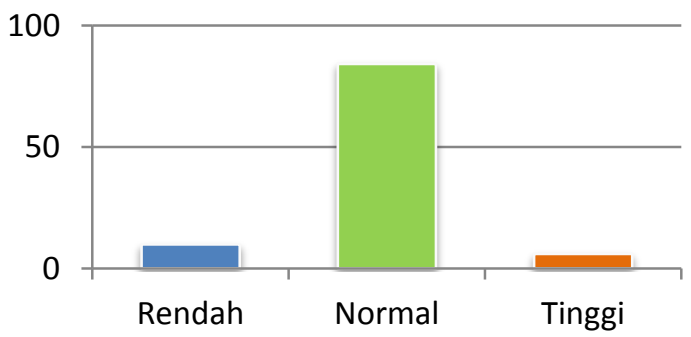

Gambar 1. Distribusi mahasiswa berdasarkan status mental menurut AGGR scales
Gambar 2 menunjukkan bahwa persentase subyek penelitian dengan skor PSYC tinggi 6,93\%, normal 90,09\%, dan rendah $2,97 \%$.

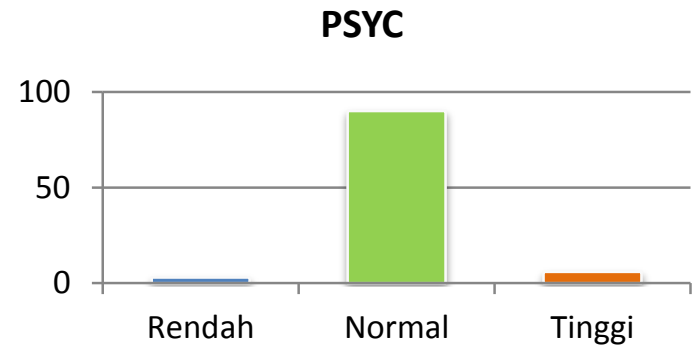

Gambar 2. Distribusi mahasiswa berdasarkan status mental menurut PSYC scales

Gambar 3 menunjukkan bahwa persentase subyek penelitian dengan skor DISC tinggi $7,92 \%$, normal $79,20 \%$, dan rendah $12,87 \%$.

DISC

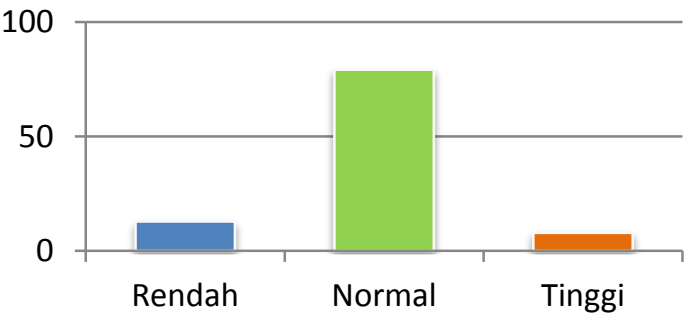

Gambar 3. Distribusi mahasiswa berdasarkan status mental menurut DISC scales

Gambar 4 menunjukkan bahwa persentase subyek penelitian dengan skor NEGE tinggi $12,87 \%$, dan normal $87,12 \%$ sedangkan yang skor rendah $0 \%$.

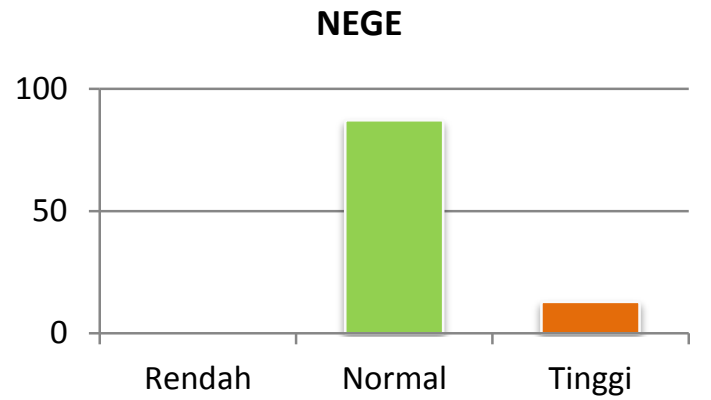

Gambar 4. Distribusi mahasiswa berdasarkan status mental menurut NEGE scales 
Gambar 5 menunjukkan bahwa persentase subyek penelitian dengan skor INTR tinggi $16,83 \%$, normal $76,23 \%$, dan rendah $6,93 \%$.

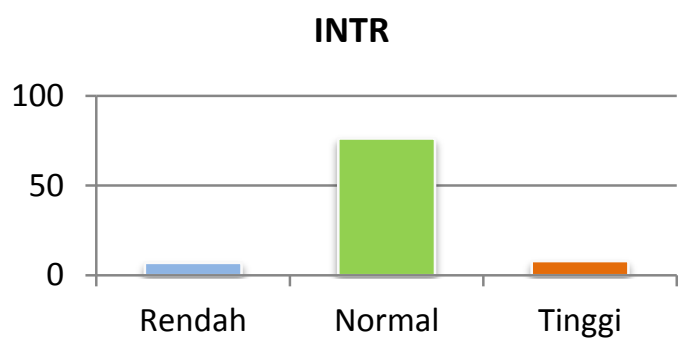

Gambar 5. Distribusi mahasiswa berdasarkan status mental menurut Introversion/Low Positive Emotionality (INTR) scales

\section{BAHASAN}

Aggresiveness (AGGR)

Menurut Gambar 1 terdapat 6 orang (5,94\%) yang memiliki skor Aggresiveness (AGGR) yang tinggi (T score >65) dari 101 responden. Tingginya skor pada skala AGGR ini mengindikasikan orang yang agresif secara fisik dan verbal, bisa menggunakan agresi untuk mendominasi dan mengontrol orang lain, senang mengintimidasi, ada riwayat bermasalah dengan sikap disekolah; jika pria sering ada riwayat melakukan kekerasan domestik, dari sisi klinis atau forensik sering didiagnosis sebagai antisocial personality disorder; dalam masa pengobatan kemungkinan ada upaya untuk mendominasi para terapis. Responden dengan skor AGGR yang rendah ( $\mathrm{T}$ score $\leq 40)$ pada skala ini hasilnya tidak diinterpretasikan.

\section{Psychoticism (PSYC)}

Data yang dipaparkan pada tabel grafik 5.2 menujukkan bahwa dari total 101 responden terdapat 7 responden $(6,93 \%)$ dengan skor PSYC tinggi ( $\mathrm{T}$ score $>65$ ). Tingginya skor PSYC mengindikasikan responden mengalami putus hubungan dengan realita, memiliki keyakinan tak wajar, sering memiliki pemikiran, pengalaman dan perasaan yang aneh, delusions of reference, memiliki riwayat kerja yang buruk, tidak memiliki keinginan yang kuat,memiliki pemikiran yang tidak realistis mengenai bahaya, merasa sering dikucilkan atau dijauhi, memiliki sedikit teman atau tidak sama sekali. Responden dengan skor PSYC yang rendah ( $\mathrm{T}$ score $\leq 40)$ pada skala ini hasilnya tidak diinterpretasikan

\section{Discontraint (DISC)}

Pada Gambar 3 dapat dilihat bahwa dari 101 responden terdapat 8 orang $(7,92 \%)$ responden yang memiliki skor DISC tinggi (Tscore >65) yang mengindikasikan responden bersifat impulsif dan tidak memiliki pengendalian diri yang baik, sering mengambil tindakan fisik yang berisiko, mudah bosan dengan rutinitas dan pergi mencari kesenangan, tidak terikat dengan moral tradisional, kemungkinan ada riwayat penyalahgunaan obat-obatan, memiliki riwayat masalah disekolah, kemungkinan ada riwayat kekerasan dan diagnosis antisocial personality disorder. Responden dengan skor DISC rendah ( $\mathrm{T}$ score $\leq 40)$ dari 101 responden terdapat 13 orang (12,87\%). Rendahnya skor ini mengindikasikan responden yang memiliki pengendalian diri dan tidak impulsif, tidak mengambi banyak tindakan fisik yang berisiko, memiliki toleransi yang tinggi akan kebosanan, mengikuti dan taat aturan/hukum.

\section{Negative emotionality/Neuroticism (NEGE)}

Gambar 4 menunjukkan bahwa dari 101 responden yang hasil tesnya valid terdapat 13 responden $(12,87 \%)$ yang mendapatkan skor tinggi ( $\mathrm{T}$ score $>65$ ) pada skala NEGE. Tingginya skor pada NEGE mengindikasikan orang yang memiliki predisposisi untuk mengalami negative affect (cemas, depresi), memandang sulit tugas yang dihadapi, selalu berpikir mengenai skenario terburuk, memiliki sedikit teman atau tidak sama sekali, sering mengkritik dirinya sendiri, sering khawatir, merasa bersalah, dapat dilaporkan sedang sedih atau tidak bersemangat, pesimis, dalam situasi klinis bisa terdapat riwayat upaya bunuh diri. Responden dengan skor NEGE yang 
rendah ( $\mathrm{T}$ score $\leq 40)$ pada skala ini hasilnya tidak diinterpretasikan

\section{Introversion/Low positive emotionality (INTR)}

Gambar 5 menunjukkan dari 101 responden terdapat 17 orang $(16,83 \%)$ yang memiliki skor INTR tinggi ( $\mathrm{T}$ score $>65$ ). Skor tinggi pada skala ini mengindikasikan responden yang sulit untuk merasakan kesenangan dan kepuasan, introvert secara sosial, memiliki keinginan berhasil yang kecil, sering merasa sedih dan tidak bersemangat, sering dilaporkan dengan adanya gejala somatik, sering merasakan kecemasan, pesimis soal masa depan, dalam situasi klinis sering didiagnosa dengan depresi, dan ada riwayat upaya bunuh diri. Untuk nilai INTR yang rendah (T score $\leq 40)$ dari 101 responden terdapat 7 orang $(6,93 \%)$. Rendahnya skor INTR mengindikasikan orang yang memiliki kapasitas untuk merasakan senang dan puas, cukup mudah bergaul,dan memiliki banyak energi. Jika skor terlalu rendah responden dapat menunjukkan gejala berupa hipomania.

\section{SIMPULAN}

Dari lima skala utama yakni aggresiveness, psychoticism, discontraint, negative emotionality/neuroticism, dan introversion/low positive emotionality didapatkan beberapa mahasiswa yang mendapatkan skor tinggi dan skor rendah. Skor tinggi pada skala aggresiveness sebesar 5,94\%; skala psychoticism sebesar 6,93\%; skala discontraint sebesar 7,92\%; skala negative emotionality/neuroticism sebesar 12,87\%; dan skala introversion/low positive emotionality sebesar $16,83 \%$. Skor terendah pada skala discontraint sebesar $12,87 \%$ dan pada skala introversion/low positive emotionality sebesar 6,93\%; skor rendah untuk skala yang lain tidak diinterpretasikan.

\section{DAFTAR PUSTAKA}

1. Hidayat DR. Permasalahan mahasiswa. [cited 21 Oktober 2013].Available from: http://www.kopertis3. or.id/ html/wpcontent/uploads/2011/04/permasalahanmahasiswa-untuk-kopertis-wilayahiii.pdf.

2. Depkes RI. Laporan hasil riset kesehatan dasar Indonesia tahun 2007. Jakarta: Badan Penelitian dan Pengembangan Kesehatan Depkes RI, 2008.

3. Ganellen RJ. Integrating the rorshach and the MMPI-2 in personality assessment. In: Weiner IB, editor. Personality and Clinical Psychology Series. New Jersey: Lawrence Elrbraum Associated, 1996; p. 1-2.

4. Graham RJ. MMPI-2. Assesing personality and psychopathology (4th ed). New York: Oxford University Press, 2006; p. 1.

5. Graham RJ. MMPI-2. Assesing Personality and Psychopathology (4th ed). New York: Oxford University Press, 2006; p. 114-51. 